\title{
EDITORIAL
}

\section{Changing Infection Patterns}

\author{
New Evidence on the Prevalence of Nosocomial Infections and Antibiotic \\ Resistance in Hospitals in Germany
}

\section{Gérard Krause}

Editorial to accompany the articles:

"The Prevalence of Nosocomial Infection and Antibiotic Use in German Hospitals" by Michael Behnke et

\section{al.}

and

„Surveillance of Antibiotic Use and Resistance in Intensive Care Units (SARI)—A 15-year Cohort Study" by Cornelius

Remschmidt et al.

in this issue of Deutsches Ärzteblatt International

Helmholtz Centre for Infection Research German Centre for Infection Research

Hannover Medical School

Prof. Dr. med. Krause
O $\mathrm{n}$ the following pages, working groups of authors from the national reference center for the surveillance of hospital-acquired infections present two longitudinal studies - one on rates of nosocomial infections in hospitals and the other on rates of antibiotic resistance in German intensive care units. In the two past decades, numerous initiatives, support programs, and even changes to the law were undertaken in response to this complex problem, and the question arises whether any improvement has materialized in the meantime.

As regards the spread of nosocomial infections, the evaluation by Behnke et al. indicates actual improvements. In a sample of 49 acute hospitals that is representative for Germany, the prevalence of patients with nosocomial infections fell by more than $25 \%$ between 2011 and 2016 (1). This sounds almost too good to be true. The prevailing view for a long time was that only one-third of all nosocomial infections were preventable (2). However, several studies in the meantime have indicated that a far greater proportion of nosocomial infections can be prevented than had been hitherto assumed, and this seems to be happening now $(3,4)$. However, when looking at only those hospitals that participated in the study in 2011 as well as in 2016, this trend was not reproducible, which makes the interpretation of the study results rather more difficult.

\section{Heterogeneous situation regarding hygiene in acute hospitals}

If one assumes that these clear improvements are a fact, the ensuing question is how they came to pass. The authors present some appropriate trends in support: the prevalence of patients treated with antibiotics in the same hospitals fell by $8 \%$ over the same period. Relative to the number of beds, the number of infection prevention and control doctors and infection prevention and control nurses roughly doubled; simultaneously, the use of alcoholic disinfectant hand rub rose by about one-fifth per patient day (1). However, acute hospitals are subject to great heterogeneity; the presented data can be interpreted only in the sense of an ecological comparison and do not permit causal associations. Accordingly, the recommendations proffered by the authors are plausible, but they cannot be concluded from the presented analysis. This is a pity because the data collected in this study seem to be suitable for establishing associations between processes and structures on the one hand, and results on the other hand. By doing so, e.g. through multivariate analysis, we could gain more evidence towards the effectiveness of applied prevention strategies.

\section{Increasing antibiotic resistance in intensive care units}

The article by Remschmidt et al. focuses on antibiotic use and rates of antibiotic resistance in 77 intensive care units between 2001 and 2015. The ICUs voluntarily participated in the project on surveillance of antibiotic use and resistance in intensive care units (Projekt zur Surveillance der Antibiotika-Anwendung und bakteriellen Resistenzen auf deutschen Intensivstationen, SARI) (5). In contrast to the previously discussed study in acute hospitals, the authors found a 19\% increase in antibiotic use in SARI ICUs. For carbapenem antibiotics, the increase was very high, at $230 \%$. The proportion of methicillin-resistant Staphylococcus aureus (MRSA) isolates has been stable for a fair while now, and since 2011, a previous increase in Escherichia coli and Klebsiella pneumoniae strains with resistance to third generation cephalosporins has also been leveling out. By contrast, rates of vancomycin resistance in Enterocococcus faecium isolates increased by a factor of 6 during the study period, and imipenem resistance among gram-negative pathogens also clearly increased during the past five years; consequently, gram-negative bacteria accounted for about half of the resistance burden. Some methodological aspects can explain why this increase was not equally pronounced in the above mentioned study in acute hospitals, in the antibiotic resistance surveillance (ARS) program of the Robert Koch-Institute (RKI), nor in the Europe-wide data collection of the European Centre for Disease Control and Prevention (ECDC) $(1,6,7)$.

In sum, both studies confirm the discovery that changes to prescribing behaviors presumably contributed primarily to selection pressure in gram negative bacteria, with the result that therapeutic options at the hospital bed are now clearly limited. This means that even in hospitals, and especially in intensive care units, all options for rational, individually tailored infection medicine will have to be extended, without neglecting general hygiene measures while doing so. It is especially in this setting that the study reported by Behnke et al. showed impressive improvements to healthcare processes and structures that have been achieved in recent years (1). For this reason, the 
recommendation that was emphasized in both studies - namely, that antibiotic stewardship should be extended-is entirely plausible $(1,5)$. But what is urgently needed is studies designed and funded to investigate the effectiveness of relevant prevention strategies in a methodologically robust way.

\section{Effectiveness of measures requires better evidence}

The bad news is that with regard to antibiotic resistance, we are still faced with huge challenges, especially in view of gram-negative pathogens.

The good news is that thanks to long-term data collections, such as the two studies published on the following pages, and also thanks to the data collection systems of the RKI and ECDC, we are able to document changes and adapt our strategies.

The next, urgently needed, step is to rationalize methodologically the indicators for processes, structures, and results in such a way that the effectiveness of the measures can be estimated. It is therefore also highly desirable for more hospitals to participate in relevant networks. The recent support program for medical informatics initiated by the Federal Ministry of Education and Research will hopefully contribute to reducing the staff hours and associated costs incurred by such data collections.

Conflict of interest statement

The author declares that no conflict of interest exists.

\section{REFERENCES}

1. Behnke M, Aghdassi SJ, Hansen S, Peña Diaz LA, Gastmeier $P$, Piening B: The prevalence of nosocomial infection and antibiotic use in German hospitals. Dtsch Arztebl Int 2017; 114: 851-7.

2. Geffers C, Gastmeier P: Häufigkeit und Vermeidbarkeit nosokomialer Infektionen - Eine Hochrechnung für Deutschland. KrankenhausHygiene + Infektionsverhütung 2010; 32: 140-3.

3. Pronovost P, Needham D, Berenholtz S, et al.: An intervention to decrease catheter-related bloodstream infections in the ICU. N Engl J Med 2006; 355: 2725-32.

4. Schmier JK, Hulme-Lowe CK, Semenova S, et al.: Estimated hospita costs associated with preventable health care-associated infections if health care antiseptic products were unavailable. Clinicoecon Outcomes Res 2016; 8: 197-205.

5. Remschmidt C, Schneider S, Meyer E, Schroeren-Boersch B, Gastmeier P, Schwab F: Surveillance of antibiotic use and resistance in intensive care units (SARI) - a 15-year cohort study. Dtsch Arztebl Int 2017; 114: 858-65.

6. Noll I, Abu Sin M, Eckmanns T: Antibiotikaresistenz - Vergleich mit Europäischen Daten. Dtsch Arztebl 2017; 114: A-2209.

7. European Centre for Disease Prevention and Control (ECDC): Summary of the latest data on antibiotic resistance in the European Union. EARS-Net surveillance data, November 2016. ecdc.europa. eu/sites/portal/files/documents/antibiotics-EARS-Net-summary-2016_0.pdf (last accessed on 30 November 2017).

\section{Corresponding author:}

Prof. Dr. med. Gérard Krause

Inhoffenstr. 7

38124 Braunschweig

gerard.krause@helmholtz-hzi.de

\section{Cite this as:}

Krause G: Changing infection patterns-new evidence on the prevalence of nosocomial infections and antibiotic resistance in hospitals in Germany. Dtsch Arztebl Int 2017; 114: 849-50. DOl: 10.3238/arztebl.2017.0849 